\title{
Influence of the salt concentration on action mechanisms of natamycin against microorganisms of importance in food manufacture
}

\author{
Kamila Ferreira Costa SERAFINI ${ }^{1 *}$ (D), Ernandes Rodrigues ALENCAR ${ }^{1}$, Jaqueline Lamounier RIBEIRO ${ }^{1}$, \\ Márcia de Aguiar FERREIRA ${ }^{1}$
}

\begin{abstract}
The objective of this study was to evaluate the influence of salt concentration on action of natamycin on important microorganisms in food manufacturing as this preservative has been used in immersion baths in several dairy products in the country. Strains of Candida albicans, Escherichia coli and Staphylococcus aureus were inoculated at different saline and peptone water concentrations and received natamycin treatments. These solutions were maintained at $12^{\circ} \mathrm{C}$ and the behavior of the microorganisms evaluated at 0,24 and 48 hours (T0, T1 and T2). Each microorganism was assessed in isolation as well as the association of C. albicans and E. coli. Under the conditions proposed by the research, it was possible to conclude that $0.025 \%$ natamycin has no efficacy on C. albicans inoculated at saline concentrations below 5\%. The results obtained in E. coli counts suggest that natamycin may interfere with its development even at concentrations that may be considered low $(0.1 \%)$ and at salinity conditions of $7.5 \%$ to $10 \%$. The association of natamycin with sodium chloride potentiates its antimicrobial action, which can represent an economy and its use is amplified by the industries.
\end{abstract}

Keywords: preservatives; brine; pathogenic microorganisms.

Practical Application: This study generated knowledge for the practical application of natamycin in brine for cheeses. From this study it was possible to conclude that the association of natamycin with sodium chloride potentiates the antimicrobial action of natamycin, which may represent an economy, and its use be amplified by the industries.

\section{Introduction}

Natamicin is a macrolide antifungal polyene produced by strains of Streptomyces, as S. natalensis, S. chattanoogensise, S. lydicus (Atta et al., 2015), and is used in humans for topical treatment of bacterial and fungal keratitis, mouth, skin and vaginal infections, and in the food industry as a preservative for cheeses, salamis, yogurts, and, in some countries, juices and wines (Dalhoff \& Levy, 2015).

This antimicrobial is part of the group of preservatives in the list of food additives authorized in the European Union and is approved by the US FDA for application on cheeses surface (European Food Safety Authority, 2009). The effect of natamycin on the development of bacteria, protozoa and viruses is considered to be inexpressive and, therefore, poorly studied (Ramos et al., 2012; Dalhoff \& Levy, 2015). However, Atta et al. (2015) demonstrated that natamycin produced by S. lydicus showed effective action against Candida albicans and several bacteria such as Staphylococcus aureus, Escherichia coli, Klebsiella pneumoniae and Pseudomonas aeruginosa, and molds and yeasts.

In the Brazilian regulation regarding the production of cheeses (Brasil, 1996) natamycin is included as an additive for use as conservative surface with a maximum limit of $1.0 \mathrm{mg} / \mathrm{dm}^{2}$ not detectable at $2 \mathrm{~mm}$ depth, being absent in the mass. Although the recommendation of the use of natamycin in cheese production is limited to spraying or immersion in aqueous solutions, with concentrations varying from $0.1 \%$ to $0.4 \%$ (Laurindo, 2017), in practice it is possible to verify its use as a coadjuvant in the treatment of brine for cheeses. Such use has become widespread, and the concentration used in brine tanks is usually $0.025 \%$ natamycin.

According to data from the Ministry of Health, milk and its derivatives are among the foods involved in food outbreaks in the country from 2000 to 2017 (Brasil, 2018). Some authors indicate that $E$. coli and $S$. aureus are among the main etiological agents involved in these outbreaks (Brasil, 2018) and both microrganisms have the capacity of to develop in environments with high salinity (How et al., 2013)

Other microorganisms such as yeast Candida albicans can also contaminate food by manipulation (Medeiros et al., 2012); this microorganism is an opportunistic pathogen which can proliferate when there is an imbalance of the microbiota in the environment also can develop in environments with low water activity (Tortora et al., 2017).

In July 2015 at the 38th Session of the Codex Alimentarius Commission in Geneva, was defined the need to revise the parameters of preservatives based on sorbates, propionates, nisin and natamycin. These preservatives are currently permitted in mozzarella-type cheese by the standards defined by Codex Standard for mozzarella (Food and Agriculture Organization 
of the United Nations, 2011). At the occasion, each country was asked to express its opinion on the technological justification for the use of natamycin in this cheese (Food and Agriculture Organization of the United Nations, 2015) demonstrating the great interest in the evaluation of this antimicrobial in the dairy industry.

Recently, the food industry showed an increasing interest in antimicrobial substances to enhance food safety and product shelf life, therefore the objective of this research was to verify the influence of the salt concentration on action mechanisms of natamycin against on the development of E. coli, S. aureus and C. albicans, as well as its effect on the association of C. albicans with $E$. coli, in order to verify their effectiveness under these conditions.

\section{Material and methods}

\subsection{Inoculum preparation}

For inoculum preparation Staphylococcus aureus strains ATCC12600, Escherichia coli ATCC 25922 and Candida albicans SC5314 were used, which were inoculated in $0.85 \%$ saline so as to obtain a degree of turbidity corresponding to tube 1 of the McFarland scale (Nefelobac ${ }^{\circledast}$, Probac do Brasil), which represents a concentration of approximately $3.0 \times 10^{8} \mathrm{CFU} \mathrm{mL}$. After the initial concentration was established, successive dilutions were carried out in order to reach the approximate concentration of $3.0 \times 10^{4} \mathrm{CFU} / \mathrm{mL}$ of the microorganisms tested. The natamycin used was Delvocid Plus ${ }^{\circledR}$ (Delvocid, DSM Food Specialties).

Evaluation of the effect of different combinations of concentrations of natamycin and saline solution on S. aureus, E. coli and C. albicans

Different combinations of concentrations of natamycin and saline solution were adopted for S. aureus and E. coli. For these species of microorganisms, the concentrations of natamycin tested were 0.00 (control), $0.025,0.05$ and $0.1 \%$ $(w / v)$. Concentrations of saline solution were equivalent to $0.85,2.00,5.00,7.00$ and $10.00 \%(\mathrm{w} / \mathrm{v})$. With respect to C. albicans and the association of $C$. albicans and E. coli, combinations $0.025 \%(\mathrm{w} / \mathrm{v})$ of natamycin and concentrations of saline solution equivalent to $0.85,2.00,5.00,7.00$ and $10.00 \%(\mathrm{w} / \mathrm{v})$ were evaluated.

Evaluation of the effect of different concentrations of natamycin on S. aureus, E. coli and C. albicans in peptone water

Different concentrations of natamycin in peptone water on C. albicans, E. coli, S. aureus and for association of C. albicans and E. coli were evaluated. For E. coli and S. aureus, the concentrations of natamycin equivalent to 0.00 (control), $0.025,0.05$ and $0.1 \%$ $(\mathrm{w} / \mathrm{v})$ were adopted. For C. albicans and association of C. albicans and E. coli the $0.025 \%(\mathrm{w} / \mathrm{v})$ concentration of natamycin was evaluated.

\subsection{Microbiological analyzes}

The counts of the different species of microorganisms were carried out immediately after the exposure to the different treatments and after 24 and 48 hours, being kept at a temperature around $12{ }^{\circ} \mathrm{C}$. For the counts of S. aureus, E. coli and C. albicans the Rida ${ }^{\circledR}$ Count Staph system was used. Aureus, Rida ${ }^{\circledR}$ Count E. coli/Coliform and Rida ${ }^{\circledR}$ Count Yest \& Mold Rapid (RBiopharm AG, Darmstadt, Germany) were used for counting S. aureus, E. coli and $C$. albicans, respectively according to the manufacturer's recommendations. The dilutions adopted were 1:10 and 1:100. The results of the counts of the microorganisms surveyed were converted into $\log 10$.

\subsection{Experimental design}

A completely randomized design was used in triplicate. In the evaluation of the effect of natamycin on S. aureus and E. coli, a $4 \times 5 \times 3$ factorial scheme was adopted: four concentrations of natamycin $(0.00,0.025,0.05$ e $0.1 \%(\mathrm{w} / \mathrm{v}))$, five concentrations of saline solution $(0.85 ; 2.00 ; 5.00 ; 7.50 ; 10.00 \%(\mathrm{w} / \mathrm{v}))$ and three evaluation periods $(0,24 \mathrm{e} 48 \mathrm{~h})$. In the evaluation of the effect of natamycin on C. albicans and on C. albicans and associated E. coli, a $5 \times 3$ factorial scheme was adopted, with five concentrations of saline solution $(0.85,2.00,5.00,7.50,10.00 \%$ $(\mathrm{w} / \mathrm{v}))$ and three evaluation periods $(0,24$ and $48 \mathrm{~h})$. Regression analysis was performed, and the graphs were plotted with Sigma Plot 10.0 software. Descriptive statistics were used in the analysis of the effect of natamycin on S. aureus, E. coli and C. albicans inoculated in peptone water.

\section{Results and discussion}

C. albicans was submitted to treatments in different salt solutions and in peptone water added $0.025 \%$ natamycin, which according to observations in industries corresponds to the concentration used in the brines. However, only from inoculation in 5\% saline solution, and in 48 hours no yeast development was observed (Figure 1 and Table 1). When the yeast was inoculated in peptone water, no elimination was observed at any of the evaluated times, only a tendency towards reduction indicating that the presence of organic matter in the cheese brine may interfere with the antimicrobial action (Table 2).

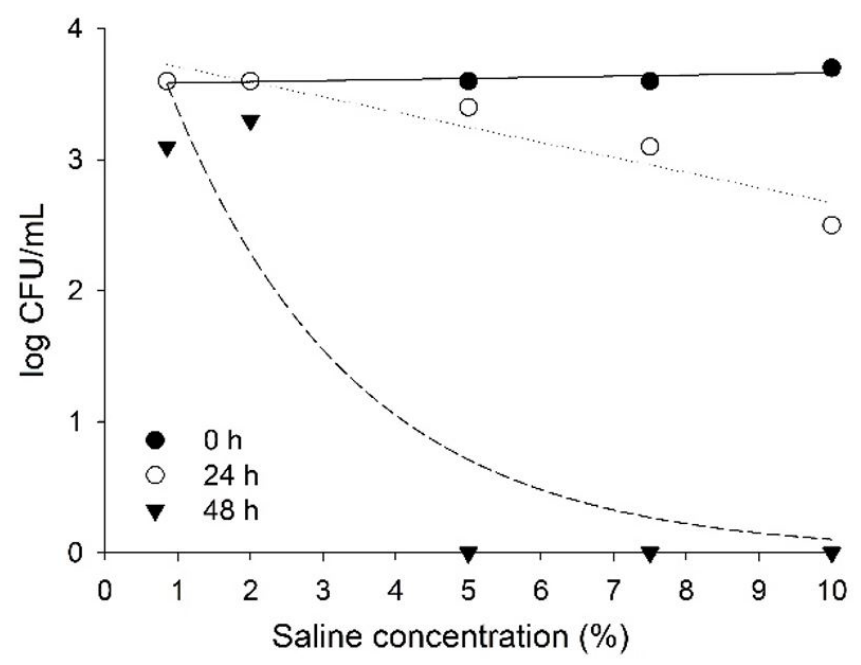

Figure 1. Counts $(\log \mathrm{CFU} / \mathrm{mL})$ of C. albicans after addition of natamycin $(0.025 \%)$, at 0,24 and $48 \mathrm{~h}$ and different salt concentrations. 
Most of the fungi have developmental capacity under low water activity (Soares et al., 2017) which can be achieved of addition of sodium chloride as carried out in this research. However, in the evaluation of the effect of natamycin $0.025 \%$ on an association of $C$. albicans with E. coli, no development of the yeast was observed after 24 hours, either when inoculated in saline solution or in peptone water (Figure 2A and Table 3).

According to Tortora et al. (2017), C. albicans is an opportunistic pathogen that can proliferate when the bacterial microbiota of the medium is suppressed. In the assay containing

Table 1. Adjusted regression equations and previous correlation coefficient to the C. albicans count $(\log \mathrm{CFU} / \mathrm{mL})$ after addition of natamycin $(0.025 \%)$, for 0,24 and $48 \mathrm{~h}$ at different salt concentrations.

\begin{tabular}{ccc}
\hline Exposure period $(\mathrm{h})$ & Adjusted regression equation & $\mathrm{R}^{2}$ \\
\hline 0 & $\hat{\mathrm{y}}=3.58$ & - \\
24 & $\hat{\mathrm{y}}=3.82-0.12^{*} X$ & 0.90 \\
48 & $\hat{\mathrm{y}}=4.99 e^{-0.39^{*} X}$ & 0.85 \\
\hline
\end{tabular}

${ }^{\star}$ Significant at $5 \%$ probability. only C. albicans, development was observed that was inhibited by natamycin from 48 hours when in saline solution greater than $5 \%$. However, in the association of C. albicans with E. coli, the presence of the bacteria in the medium prevented the growth of yeast. This result corroborates the study of Peleg et al. (2010), in which interactions between C. albicans and bacteria were reported and have been associated with reduced fungal viability, which can be attributed to the secretion of antifungal molecules by bacteria, the direct transfer of toxins from bacteria to fungal cells or by the depletion of nutrients.

These interactions, added to the action of natamycin on C. albicans and E. coli, lead to a reduction in the final count of these microorganisms. Natamycin has an antimycotic action because of its preference for ergosterol, a sterol present especially in the cell membrane of fungi and little found in bacteria (Ciesielski et al., 2016).

The E. coli counts in this association showed reductions greater than one log cycle only at the evaluations after 48 hours when inoculated in $2.0 \%, 5.0 \%$ and $7.5 \%$ saline solutions and no growth of the yeast was observed when in saline solution $10.0 \%$

Table 2. Mean results obtained in the evaluation of the effect of natamycin on the counts (log CFU/mL) of Staphylococcus aureus, Escherichia coli and Candida albicans inoculated in peptone water.

\begin{tabular}{|c|c|c|c|c|}
\hline \multirow{2}{*}{\multicolumn{2}{|c|}{ Treatments / Weather }} & \multicolumn{3}{|c|}{ Peptone water } \\
\hline & & Oh & $24 \mathrm{~h}$ & $48 \mathrm{~h}$ \\
\hline \multirow[t]{2}{*}{ C. albicans } & Natamycin $0.025 \%$ & 3.6 & 3.5 & 3.0 \\
\hline & Control & 4.2 & 4.8 & Countless \\
\hline \multirow[t]{4}{*}{ S. aureus } & Natamycin $0.025 \%$ & 4.2 & 4.8 & Countless \\
\hline & Natamycin $0.05 \%$ & 4.4 & 4.9 & Countless \\
\hline & Natamycin $0.1 \%$ & 4.0 & 4.2 & 4.6 \\
\hline & Control & 4.5 & 5.9 & 6.7 \\
\hline \multirow[t]{3}{*}{ E. coli } & Natamycin $0.025 \%$ & 4.5 & 5.9 & 6.3 \\
\hline & Natamycin $0.05 \%$ & 4.5 & 5.8 & 6.0 \\
\hline & Natamycin $0.1 \%$ & 4.5 & 5.8 & 6.0 \\
\hline C. albicans / E.coli & Natamycin $0.025 \%$ & $4.0 / 4.9$ & $0 / 4.7$ & $0 / 4.5$ \\
\hline
\end{tabular}

A

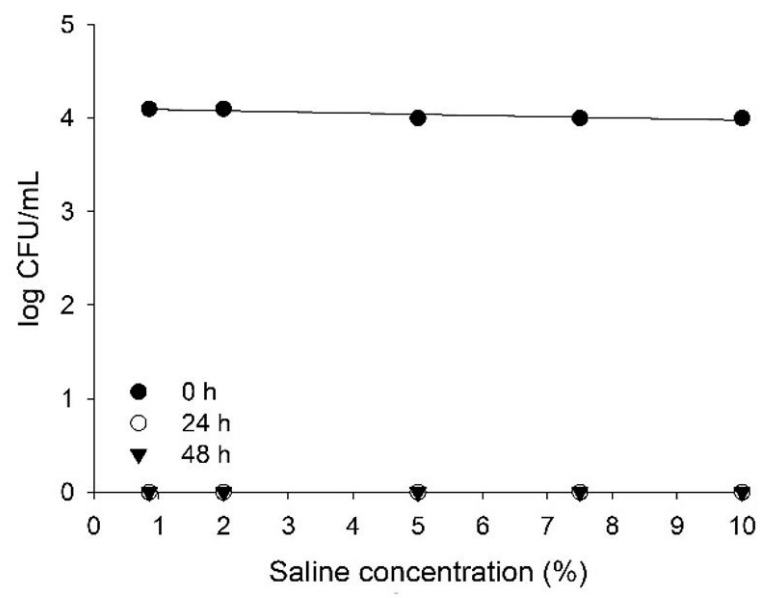

B

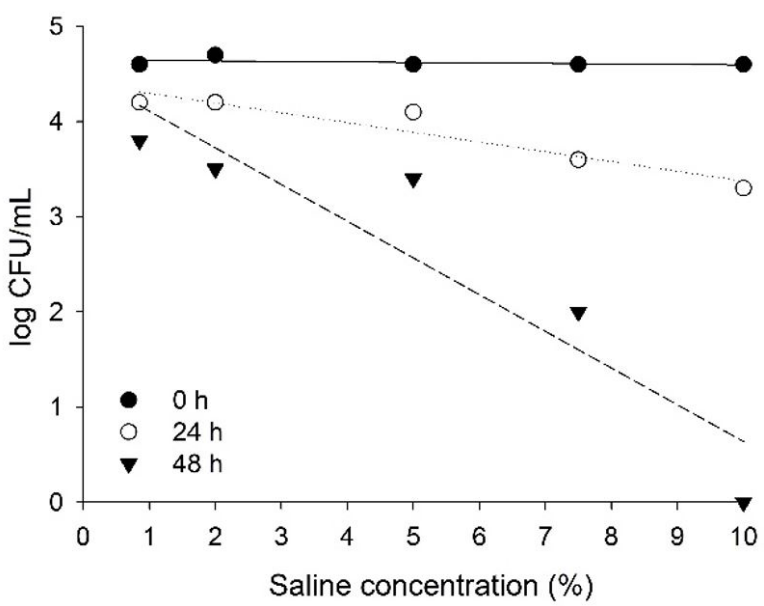

Figure 2. Counts $(\log \mathrm{CFU} / \mathrm{mL})$ of C. albicans $(\mathrm{A})$ and E. coli (B) when in association with and after addition of natamycin (0.025\%), at 0,24 and $48 \mathrm{~h}$, at different saline concentrations. 
(Figure 2B and Table 3). When the association was performed in peptone water, there was no reduction in E. coli counts (Table 2).

In the trials performed with $S$. aureus, no reduction was observed in any of the evaluated treatments and in the inoculations in peptone water, the counts increased significantly (Table 2).

Table 3. Adjusted regression equations and respective determination coefficients for the counts $(\log \mathrm{CFU} / \mathrm{mL})$ of C. albicans $(\mathrm{A})$ and E. coli (B) when associated and exposed to natamycin (0.025\%), for 0,24 and $48 \mathrm{~h}$ in different concentrations.

\begin{tabular}{lccc}
\hline Species & $\begin{array}{c}\text { Period of } \\
\text { exposure }(\mathrm{h})\end{array}$ & $\begin{array}{c}\text { Adjusted } \\
\text { regression } \\
\text { equation }\end{array}$ & $\mathrm{R}^{2}$ \\
\hline C. albicans & 0 & $\hat{\mathrm{y}}=4.10$ & - \\
& 24 & $\hat{\mathrm{y}}=0$ & - \\
& 48 & $\hat{\mathrm{y}}=0$ & - \\
E. coli & 0 & $\hat{\mathrm{y}}=4.65$ & - \\
& 24 & $\hat{\mathrm{y}}=4.40-0.10^{*} \mathrm{X}$ & 0.90 \\
& 48 & $\hat{\mathrm{y}}=4.50-0.39^{*} \mathrm{X}$ & 0.86 \\
\hline *Significant & & &
\end{tabular}

${ }^{\star}$ Significant at $5 \%$ probability.
Ramos et al. (2012), in a study with edible films, stated that natamycin has no action against bacteria. S. aureus is a Gram positive bacterium and its cell wall consists of many layers of peptideoglycan that form a thick and rigid structure that can prevent the action of some antimicrobials on the microorganism (Tortora et al., 2017). However, Atta et al. (2015) demonstrated that an antimicrobial compound produced by Streptomyces lydicus and classified as natamycin showed activity against Gram positive bacteria such as S. aureus, Micrococcus luteus and Bacillus subtilis. In action on E. coli, reductions of up to one log cycle in the counts after 24 hours were observed in the treatments with addition of natamycin $0.025,0.05$ and $0.1 \%$ from $7.5 \%$ saline solution (Figure $3 \mathrm{~B}$ and Table 4 ). In these same treatments after 48 hours, reductions greater than one log cycle were observed from treatments in $7.5 \%$ saline solution (Figure 3C and Table 4).

When the bacterium was inoculated in peptone water, none of the concentrations of natamycin evaluated, was able to promote reduction of the counts, including increases $\geq 1.5 \log$ cycles in the final counts (Table 2), suggesting that the availability of substrate may accelerate bacterial metabolism and render antimicrobial action unfeasible. According to information obtained from the manufacturer it is recommended to add $5-10 \%$ salt to the immersion bath to limit bacterial growth on the cheese shell. However, the
A

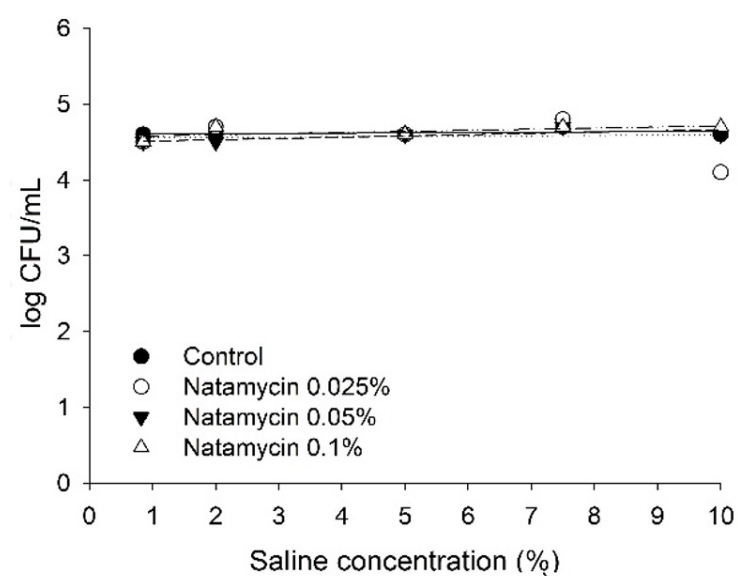

B

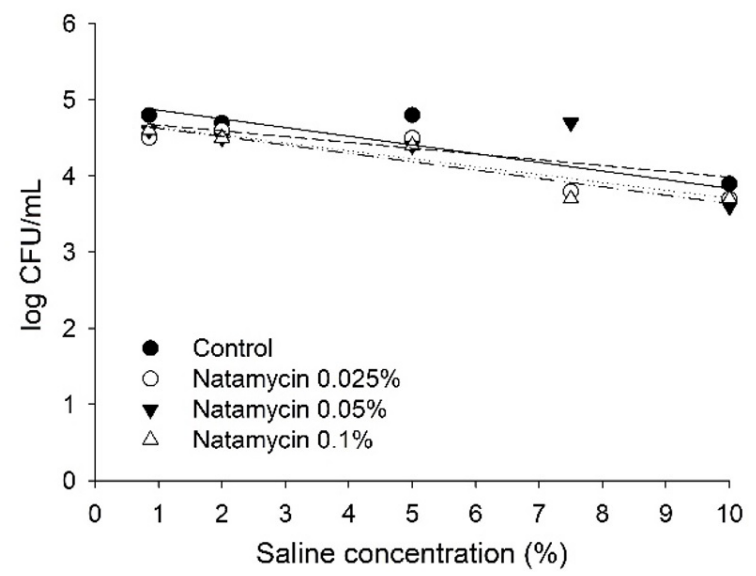

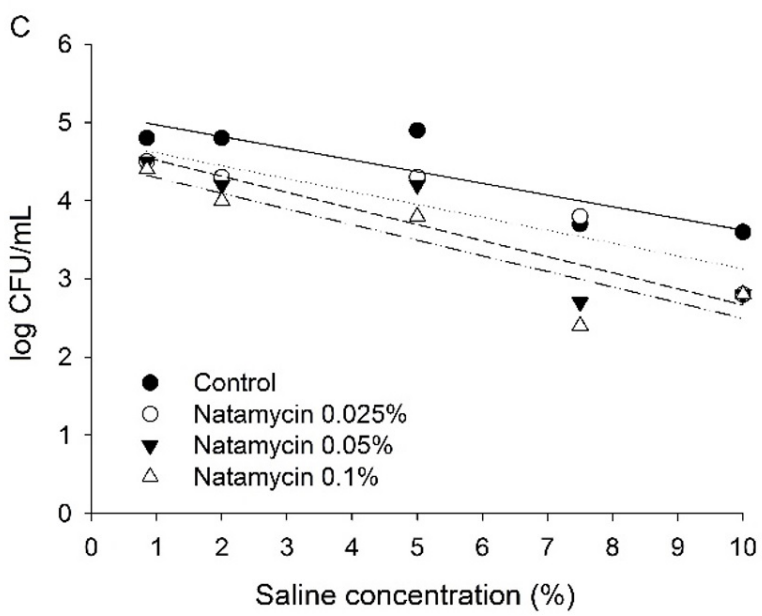

Figure 3. Counts $(\log \mathrm{CFU} / \mathrm{mL})$ of E. coli. after addition of natamycin at $0(\mathrm{~A}), 24(\mathrm{~B})$ and $48 \mathrm{~h}(\mathrm{C})$ and different saline concentrations. 
Table 4. Adjusted regression equations and respective determination coefficients for $E$. coli counts ( $\log \mathrm{CFU} / \mathrm{mL}$ ) after addition of natamycin $(0,0.025,0.05$, and $0.1 \%)$ in $0(\mathrm{~A}), 24(\mathrm{~B})$ and $48 \mathrm{~h}(\mathrm{C})$ at different salt concentrations.

\begin{tabular}{|c|c|c|c|}
\hline $\begin{array}{c}\text { Period of } \\
\text { exposure (h) }\end{array}$ & $\begin{array}{c}\text { Concentration of } \\
\text { natamycin (\%) }\end{array}$ & $\begin{array}{c}\text { Adjusted regression } \\
\text { equation }\end{array}$ & R2 \\
\hline \multirow[t]{4}{*}{0} & Control -0 & $\hat{y}=4.60$ & - \\
\hline & 0.025 & $\hat{y}=4.36$ & - \\
\hline & 0.050 & $\hat{y}=4.49$ & - \\
\hline & 0.100 & $\hat{y}=4.57$ & - \\
\hline \multirow[t]{4}{*}{24} & Control -0 & $\hat{y}=4.98$ & - \\
\hline & 0.025 & $\hat{y}=4.75-0.10^{*} \mathrm{X}$ & 0.82 \\
\hline & 0.050 & $\hat{y}=4.75-0.08^{*} x$ & 0.43 \\
\hline & 0.100 & $\hat{y}=4.74-0.11^{*} \mathrm{X}$ & 0.88 \\
\hline \multirow[t]{4}{*}{48} & Control -0 & $\hat{y}=5.12$ & - \\
\hline & 0.025 & $\hat{y}=4.77-0.16^{*} x$ & 0.82 \\
\hline & 0.050 & $\hat{y}=4.72-0.21^{*} X$ & 0.82 \\
\hline & 0.100 & $\hat{y}=4.49-0.20^{*} \mathrm{X}$ & 0.81 \\
\hline
\end{tabular}

${ }^{*}$ Significant at $5 \%$ probability.

results showed that at the recommended concentration $(0.025 \%)$, natamycin had an effect on the bacterium only when in $7.5 \%$ saline solution after 24 hours indicating that only immersion may not be efficient to limit the bacterial development referred to. According to Atta et al. (2015) the natamycin produced by $S$. lydicus presents effective antimicrobial action against E. coli, Klebsiella pneumonia and Pseudomonas aeruginosa.

Unlike S. aureus, the effect of natamycin on E. coli may be due to the fact that this bacterium is Gram negative and has a cell wall formed by one or a few layers of peptideoglycan and an outer membrane that does not provide a barrier to all substances in the environment, being more permeable due to the presence of porins that form channels that allow the passage of certain molecules, being even more susceptible to mechanical rupture (Tortora et al., 2017).

E. coli is not a bacterium considered halotolerant, however several studies have demonstrated its capacity to develop tolerance to extreme saline concentrations. Hrenovic \& Ivankovic (2009) carried out research with the objective of verifying the resistance of this bacterium in marine environments, when coming from domestic sewage or effluent from treatment stations, noting that the elimination of the bacteria occurred only in concentrations of $20 \%$ salt in 72 hours and $30 \%$ in 48 hours, maintaining multiplication activity in salt concentrations above $5 \%$. How et al. (2013) demonstrated the ability of E. coli to adapt to different salt concentrations (from $0 \%$ to $10 \%$ ) and after 60 passages to be able to increase its tolerance by $1 \%$, multiplying in environments with $11 \%$ saline concentration.

\section{Conclusion}

Under the conditions proposed by the research, it was possible to conclude that $0.025 \%$ natamycin has no efficacy on Candida albicans inoculated at saline concentrations below 5\%. When yeast was associated with Escherichia coli showed susceptibility to the proposed treatments, however the reduction in counts may be due to the low capacity of the same to develop when in association with other microorganisms. The results obtained in the E. coli counts showed that natamycin may interfere with its development, even at concentrations considered low (0.1\%) and at salinity conditions of $7.5 \%$ to $10 \%$. Thus, the association of natamycin with sodium chloride potentiates its antimicrobial action, which can represent an economy and its use is amplified by the industries.

\section{Acknowledgements}

To the Brazilian Association of Cheese Industries in the person of teacher Maria Cristina Mosquim. To Cap-Lab and DSM for the donation of the material used to carry out this research.

\section{References}

Atta, H. M., El-Sayed, A. S., El-Desoukey, M. A., Hassan, M., \& ElGazar, M. (2015). Biochemical studies on the Natamycin antibiotic produced by Streptomyces lydicus: fermentatin, extraction and biological activities. Journal of Saudi Chemical Society, 19(4), 360371. http://dx.doi.org/10.1016/j.jscs.2012.04.001.

Brasil. (1996, March 7). Regulamento técnico para fixação de identidade e qualidade queijos (Portaria no 146, de 7 de março de 1996). Diário Oficial [da] República Federativa do Brasil.

Brasil, Coordenação Geral de Doenças Transmissíveis. (2018). Surtos de doenças transmitidas por alimentos no Brasil. Brasília. Retrieved from http://portalarquivos2.saude.gov.br/images/pdf/2018/janeiro/17/ Apresentacao-Surtos-DTA-2018.pdf

Ciesielski, F., Griffin, D. C., Loraine, J., Rittig, M., Delves-Broughton, J., \& Bonev, B. B. (2016). Recognition of membrane sterols by polyene antifungals amphotericin B and natamycin, A13C MAS NMR study. Frontiers in Cell and Developmental Biology, 4, 57. http://dx.doi. org/10.3389/fcell.2016.00057. PMid:27379235.

Dalhoff, A. A., \& Levy, S. B. (2015). Does use of the polyene natamycin as a food preservative jeopardise the clinical efficacy of amphotericin $\mathrm{B}$ ? A word of concern. International Journal of Antimicrobial Agents, 45(6), 564-567. http://dx.doi.org/10.1016/j.ijantimicag.2015.02.011. PMid:25862309.

European Food Safety Authority - EFSA. (2009). Panel on food additives and nutrient sources added to food (ANS); scientific opinion on the use of natamycin (E235) as a dood additive. EFSA Journal, 7(12), 1412-1437. http://dx.doi.org/10.2903/j.efsa.2009.1412.

Food and Agriculture Organization of the United Nations - FAO, Codex Alimentarius. (2011). Codex stan 262-2006: milk and milk products: mozzarella (2nd ed., pp. 86-92). Rome: FAO.

Food and Agriculture Organization of the United Nations - FAO, Joint FAO/WHO Food Standards Programme, Codex Alimentarius Comission. (2015). CL 2015/26: request for information on the justification of the use of preservatives and anticaking agents for surfasse treatment of mozzarella with a high moisture contente. Rome: Codex Alimentarius Commission. 
How, J. A., Lim, J. Z., Goh, D. J., Ng, W. C., Oon, J. S., Lee, K. C., Lee, C. H., \& Ling, M. H. T. (2013). Adaptation of Escherichia coli ATCC 8739 to $11 \% \mathrm{NaCl}$. Dataset Papers in Science, 2013, 1-7.

Hrenovic, J., \& Ivankovic, T. (2009). Survival of Escherichia coli and Acnetobacter junii at various concentrations of sodium chloride. EurAsian Journal of Bioscienses, 3(3), 144-151. http://dx.doi.org/10.5053/ejobios.2009.3.0.18.

Laurindo, J. (2017). Teor de natamicina, caracterização físico-química, perfil de ácidos graxos e índices de qualidade lipídica em queijo azul e tipo gorgonzola (Dissertação de mestrado). Universidade Tecnológica Federal do Paraná,Londrina.

Medeiros, M. C. Jr., Silveira, G. S., Pereira, J. B. B., Chavasco, J. M., \& Chavasco, J. K. (2012). Verificação de contaminantes de natureza fecal na superfície de torneiras de banheiros públicos. Revista da Universidade Vale do Rio Verde, 10(1), 297-303. http://dx.doi. org/10.5892/ruvrv.2012.101.297303.
Peleg, A. Y., Hogan, D. A., \& Mylonakis, E. (2010). Medically important bacterial-fungal interactions. Nature Reviews. Microbiology, 8(5), 340-349. http://dx.doi.org/10.1038/ nrmicro2313. PMid:20348933.

Ramos, Ó. L., Silva, S. I., Soares, J. C., Fernandes, J. C., Poças, M. F., Pintado, M. E., \& Malcata, F. X. (2012). Featuresad performance of edible films, obtained from whey protein isolate formulated with antimicrobial compounds. Food Research International, 45(1), 351361. http://dx.doi.org/10.1016/j.foodres.2011.09.016.

Soares, C. E. S., Martins, C. S., Maria, G. S., \& Scussel, V. M. (2017). Fungos de armazenagem e micotoxinas em dieta para ovinos (Ovis aries L.): estudo de caso. Pubvet, 11(12), 1210-1219. http://dx.doi. org/10.22256/pubvet.v11n12.1210-1219.

Tortora, G. J., Funke, B. R., \& Case, L. C. (2017). Microbiologia (12. ed.). Porto Alegre: Artmed. 